CLINICAL STUDY

\title{
Relevance of Ki-67 and prognostic factors for recurrence/progression of gonadotropic adenomas after first surgery
}

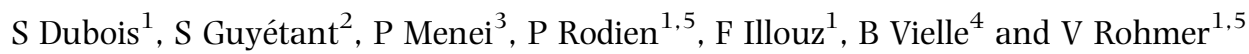 \\ ${ }^{1}$ Département d'Endocrinologie, ${ }^{2}$ Département d'Anatomopathologie, ${ }^{3}$ Département de Neurochirurgie and ${ }^{4}$ Département de Biostatistiques, Centre \\ Hospitalier Universitaire, 4 rue Larrey, 49933 Angers Cedex 09, France, and ${ }^{5}$ Université d'Angers, rue haute de Reculée, 49045 Angers cedex 01, France \\ (Correspondence should be addressed to S Dubois; Email: sedubois@chu-angers.fr)
}

\begin{abstract}
Objective: Gonadotropin-secreting pituitary adenomas carry a high risk of local recurrence or progression $(\mathrm{R} / \mathrm{P})$ of remnant tumor after first surgery. The clinical characteristics and the long-term outcome of these silent adenomas, which show no signs of endocrine hyperfunction, differ from those of other types of pituitary adenomas. However, to date, no study has focused specifically on gonadotropic adenomas.

Materials and methods: To identify prognostic factors of R/P of remnants, we studied the postoperative outcome of 32 gonadotropic pituitary adenomas, defined on immunohistochemical staining, according to their clinical and radiological characteristics as well as the Ki-67 labeling index (LI).

Results: The Ki-67 LI failed to provide independent information for the identification of patients at risk of progression of remnants or recurrence. Multivariate survival analysis (Cox regression) showed that neither invasiveness nor remnant tumors nor hyposomatotropism influenced tumor recurrence. The strongest predicting factors of $\mathrm{R} / \mathrm{P}$ were the antero-posterior (AP) diameter in the sagittal plane $(P=0.014)$, and the age of the patient at surgery $(P=0.047)$, with younger patients being at greater risk. Hazard ratios were 2.11 for each $5 \mathrm{~mm}$ increase in AP diameter and 0.57 for every 10 years of age.

Conclusion: The two simple clinical criteria revealed by our study, the AP diameter of the tumor and the age of the patient, should be helpful in planning clinical management and radiological monitoring after first surgery of gonadotropic adenomas, while awaiting the identification of other pathological parameters.
\end{abstract}

European Journal of Endocrinology 157 141-147

\section{Introduction}

Gonadotropin-secreting adenomas (GSAs) account for $\sim 12-17 \%$ of surgically treated pituitary adenomas (1, 2 ). Since GSAs show no signs of endocrine hyperfunction, their clinical characteristics and long-term outcome differ from those of other pituitary adenomas, which frequently involve extrasellar extension with mass effects, visual disturbances, and pituitary dysfunction (3). No effective medical treatment is available in the case of GSAs and surgery is the therapy of choice. However, complete resection of the tumors is rarely possible because of their large size and invasive nature. The rate of recurrence of non-functioning pituitary adenomas has been estimated at between 10 and $52 \%$ (4-7). Furthermore, the absence of any measurable hypersecretion makes early prediction of recurrence difficult (8). Given the nature of GSAs, residual tumor regrowth can only be assessed by repeated postoperative magnetic resonance imaging (MRI) examinations. As adjuvant radiotherapy is often advised in cases of recurrent pituitary adenomas, the identification of early predictors of recurrence would help to avoid unnecessary radiotherapy; indeed, the regrowth of the tumor is a very slow process and radiation injuries have been documented. Several reports on non-functioning pituitary adenomas have suggested that the risk of recurrence is contingent upon tumor size, invasiveness, and extent of surgical removal (9-11). However, such findings cannot readily apply for individual cases. Moreover, a number of common pathological features of GSAs, such as high mitotic rate, nuclear pleomorphism, necrosis, high cellularity, and cytologic atypia, have turned out to be poor predictors of outcome (2).

The MIB-1 monoclonal antibody (MAB), which discriminates between proliferating and quiescent cells by targeting the Ki-67 nuclear antigen specific to the cell cycle, has proved helpful in the prognosis of various tumors (12-16). However, the usefulness of MIB-1 in predicting the behavior of pituitary adenomas has been 
variously appreciated. Thus, Hentschel et al. (17) found no relationship between the MIB-1 labeling index (LI) and the recurrence of non-functioning pituitary adenomas; Honegger et al. (18) found a correlation between the expression of Ki-67 and the growth velocity of nonfunctioning pituitary adenomas but not with the invasive behavior; Schreiber et al. (19) demonstrated the usefulness of Ki-67 in evaluating the aggressiveness of silent pituitary adenomas; and Turner et al. (20) concluded that Ki-67 may be helpful in cases of suspected tumoral recurrence or invasiveness. Unfortunately, little information is available specifically regarding GSAs.

We have therefore investigated the clinical, radiological, and pathological characteristics as well as the Ki-67 LI in a series of GSAs to try to determine specific prognostic factors for recurrence or progression $(\mathrm{R} / \mathrm{P})$ of these tumors.

\section{Patients and methods}

\section{Patients}

Thirty-two patients (12 women and 20 men) with a median age of 58 years (range 36-73 years) were treated for GSAs exclusively by surgery at the University Hospital of Angers, France, between 1984 and 1995. All patients were followed up in the same institution until April 2001. Seven other patients with gonadotropic adenomas, surgically treated over the same period, were excluded because of insufficient data after surgery in five cases (two deaths), and because of postoperative preventive radiotherapy in two cases. None of the patients reported here received preventive radiotherapy or treatment for gonadotropic or somatotropic deficiency.

Follow-up monitoring included MRI (or CT scans prior to 1990) 2-8 months after surgery, then yearly for 5 years, and every 4 years thereafter. The presence of a postoperative remnant led to a closer follow-up with MRI twice a year for 3 years, then yearly for 5 years, and then every 2 years. None of the patients were monitored exclusively by CT scans during the entire follow-up. Scans were reviewed by two endocrinologists and a neurosurgeon (PM), blinded to the patients clinical details, treatment, and outcome. $\mathrm{R} / \mathrm{P}$ was defined as the growth of residual adenomatous tissue $>3 \mathrm{~mm}$ along one of the three diameters: the AP diameter in the sagittal plane, the rostro-caudal diameter (RC) in the coronal plane, or the transverse diameter (TR); or by the presence of pathological tissue that had not been detected by previous MRI (Fig. 1A-C). The last MRI determined the last moment of follow-up.

\section{Pathological studies and MIB-1 immunostaining}

Pathological examination was performed on paraffinembedded blocks. Fresh adenomatous tissue was initially immersed in a mixture of $0.25 \%$ glutaraldehyde and $4 \%$ paraformaldehyde for $\sim 10 \mathrm{~h}$. Then, following hematoxylin-eosin-saffron staining, $3 \mu \mathrm{m}$ thick serial sections were used for microscopic examination and immunohistochemical characterization. Immunoreactivity in 5\% of adenomatous cells was required for the diagnosis of hormonal secretion (21). Only pure gonadotropic (follicle-stimulating hormone (FSH)- $\beta$ and/or luteinizing hormone (LH)- $\beta$ and/or human chorionic gonadotropin) and $\alpha$-subunit adenomas were selected for the study; all adenomas classified as mixed adenomas on histochemical criteria, even those with predominant gonadotropic immunoreactivity, being excluded. The archival material was reviewed by one of the authors (SG) and one tissue block representative of each case was selected for Ki-67 assessment. Four cases were excluded from the Ki-67 immunostaining procedure as the corresponding tissue blocks contained no adenomatous tissue (two cases) or were composed mainly of necrotic tissue (two cases). The initial diagnosis of gonadotropic adenoma in the latter two cases was based on immunohistochemical observations made on the non-necrotic areas of the sections.

The selected blocks corresponding to the remaining 28 patients were submitted for Ki-67 evaluation. Briefly, deparaffinized sections were subjected to a microwave antigen retrieval treatment $(3 \times 5$-min immersions in a citrate buffer $(\mathrm{pH} 6)$ at $750 \mathrm{~W})$ and then stained for Ki-67 (MIB-1 MAB at 1/8 dilution; Immunotech,

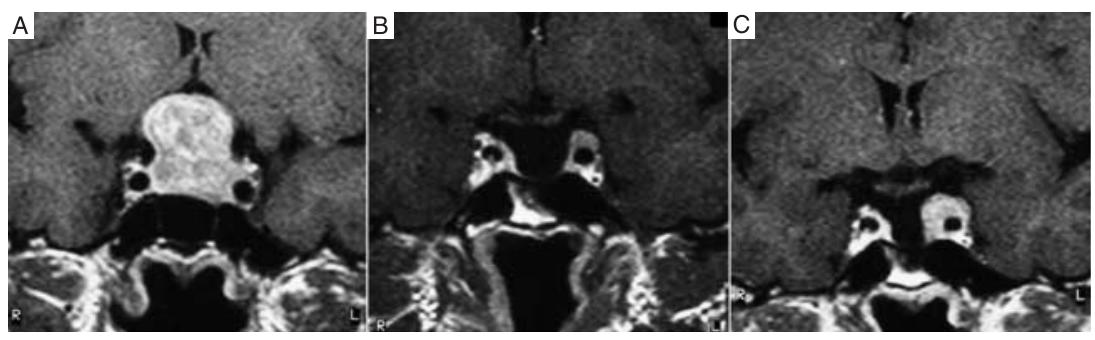

Figure 1 Coronal T1-weighted MR images with gadolinium enhancement. (A) Preoperative MRI (1993): pituitary macroadenoma with extrasellar development and invasion of the left cavernous sinus. (B) Postoperative MRI (1996): left cavernous residual tissue. (C) Postoperative MRI (2000): recurrent tumor tissue arising from residual tissue 8 years after neurosurgery. 
Marseille, France), using an avidin-biotin-peroxidase method (LSAB kit, Dako SA, Paris, France) with diaminobenzidine used as chromogen. A mild hematoxylin counterstain was chosen to obtain satisfactory morphological results and provide optimal conditions for image analysis. In each case, a slide was incubated with normal rabbit serum used as a negative control. Specific nuclear staining, observed in each adenoma, was used as an internal positive control so that no other positive control was required. As is commonly seen in other endocrine neoplasms, Ki-67-positive cells were heterogeneously distributed throughout the tumor. Following studies on proliferative activity in pituitary adenomas (22-24), we evaluated the Ki-67 LI in the areas of the tumor where Ki-67-labelled nuclei were predominant. Thus, immunostained sections were screened under the microscope, and the areas containing the greatest number of Ki-67-stained nuclei were outlined with a pencil, allowing easy localization during image analysis.

\section{Morphometry: determination of the Ki-67 LI}

Morphometry was performed without prior knowledge of the clinical data. Given that cell counting on numerous microscopic fields is known to be a source of intra- and interobserver variability, area-based image analysis software (Immuno-Analysis 4.22, Samba Technologies, Meylan, France) was used. The Ki-67 LI was calculated as the ratio between the labeled and total nuclear areas. This time-saving approach eliminates counting the nuclei, of which there are several hundred per field, and has been validated by Thapar et al. (2). Image acquisition was achieved using a light microscope equipped with a triCCD camera and a $400 \times$ magnification (field area: $42958 \mu^{2}$ ). The number of adenomatous cells per field, depending on the cellular density of the tumor, ranged from 200 to 300 cells per field. First, the image was studied using the blue channel. On this image, a threshold value was determined interactively by the operator to measure the total nuclear area. Then, the same field was examined using the green channel, highlighting labeled nuclei, i.e. Ki-67-stained nuclei, colored in brown by the chromogen, and the nuclear stained area was automatically calculated. Finally, a new measurement was made on the same image following interactive exclusion by the operator of positive adenoma nuclei. This allowed a precise measurement of the background, consisting of hemosiderin deposits, and labeled endothelial cells, which was subsequently subtracted from the initial measurement, allowing the determination of a corrected Ki-67 LI. Ten microscopic fields were examined for each case and the mean and peak LI values, noted Ki-67 LIm and Ki-67 LIp respectively, were recorded.

\section{Statistical analysis}

Results are presented as mean \pm s.D. The Kaplan-Meier product-limit method was used to estimate the survival curve. For survival analysis, the log-rank test and Cox proportional hazard model were used. Because of the small number of events (14 relapses) and the potential risk of 'over-fitting', a forward stepwise regression method was used for the multivariable analysis, leading to the three-variable model. Spearman's rank coefficient was used for studying the correlation between continuous variables. A $P$ value of 0.05 or less was considered significant.

\section{Results}

The median follow-up period was 9 years (range 4-17 years). R/P occurred in 14 of the 32 patients ( 4 women and 10 men; Table 1). The median relapse latency was 6 years (range $2-13$ years). Figure 2 shows the relapsefree probability curve. The percentage recurrence rates as estimated by the Kaplan-Meier curve were 15.7, 47.8 , and $56.5 \%$, after 5,10 , and 13 years respectively. $\mathrm{R} / \mathrm{P}$ led to abstention in three cases (mild tumor progression and no sight alteration in an 81-year-old patient, patient's refusal, pre-existing total blindness, and no further symptoms despite recurrence), repeated surgery in two cases, pituitary radiotherapy in five cases, and combined surgery and radiotherapy in four cases.

\section{Clinical findings}

All pituitary tumors were macroadenomas. The median diameters (first and third quartiles in parentheses) of the tumors along the three axes (AP, TR, and RC) on preoperative MRI examinations were as follows: $\mathrm{AP}=22(17.7 / 26) \mathrm{mm}, \mathrm{TR}=24(20.2 / 29) \mathrm{mm}$, and $\mathrm{RC}=27(21 / 32) \mathrm{mm}$. Invasion of one or both cavernous sinuses was observed in 12 of the 32 patients. Postoperative MRI revealed remnant tumors in 26 patients with $\mathrm{AP}=10.5(4.2 / 15) \mathrm{mm}, \mathrm{TR}=8(5 / 15)$ $\mathrm{mm}$, and $\mathrm{RC}=6(3 / 8) \mathrm{mm}$. Only one out of the six patients with no apparent residual tissue had a relapse.

Initial and postoperative endocrinological findings are summarized in Table 1. Six patients had preoperative increased circulating LH, FSH, or $\alpha$-subunit (Table 1). Permanent postoperative diabetes insipidus occurred in one patient. Thirty-one patients presented with preoperative visual field disorder. Clinical remission or improvement of visual function was found in 23 patients after surgery. In univariate analysis, $\mathrm{R} / \mathrm{P}$ was associated with tumor size: $\mathrm{AP}(P=0.015)$ and $\mathrm{RC}(P=$ $0.024)$, and a young age at surgery $(P=0.027$; Table 2). Multivariate analysis showed that only the AP diameter of the adenoma $(P=0.014)$ and the age at surgery $(P=0.047)$ were independent prognostic 
Table 1 Characteristics of recurrent and non-recurrent gonadotropin-secreting pituitary adenomas.

\begin{tabular}{|c|c|c|}
\hline & Non-recurrent & Recurrent \\
\hline Number & 18 & 14 \\
\hline $\begin{array}{l}\text { Age (median years; } \\
\text { range) }\end{array}$ & $61.5(47-73)$ & $55.5(36-70)$ \\
\hline \multicolumn{3}{|l|}{ Gender } \\
\hline Female & 8 & 4 \\
\hline Male & 10 & 10 \\
\hline \multicolumn{3}{|l|}{ Size } \\
\hline AP (median mm) & $18(14.5 / 24)$ & $22(20 / 27)$ \\
\hline TR (median mm) & $22.5(19.5 / 27.5)$ & $25(21 / 32)$ \\
\hline $\mathrm{RC}($ median $\mathrm{mm})$ & $26(19.5 / 28.5)$ & $31(24 / 35)$ \\
\hline Invasive & $6(33 \%)$ & $6(43 \%)$ \\
\hline Remnant tumor & $13(72 \%)$ & $13(93 \%)$ \\
\hline \multicolumn{3}{|l|}{ Recurrence time } \\
\hline Mean years & & $5.5(4 / 8)$ \\
\hline Range years & & $2-13$ \\
\hline \multicolumn{3}{|l|}{ Follow-up time } \\
\hline Median years & $8.5(6 / 13)$ & $10(9 / 13)$ \\
\hline Range years & $4-17$ & $8-17$ \\
\hline \multicolumn{3}{|l|}{ Ki-67 } \\
\hline Median LIm (\%) & $1.11(0.43 / 1.5)$ & $1.10(0.52 / 1.67)$ \\
\hline Median LIp (\%) & $1.92(1.15 / 2.04)$ & $1.76(0.79 / 2.42)$ \\
\hline Serum hormonal & 3 & 3 \\
\hline \multicolumn{3}{|l|}{ Hypersecretion } \\
\hline $\mathrm{LH}$ & 0 & 1 \\
\hline $\mathrm{FSH}$ & 2 & 2 \\
\hline$\alpha$-Subunit & $\overline{1}$ & 0 \\
\hline \multicolumn{3}{|c|}{ Preoperative hormonal deficiency } \\
\hline Single deficiency & $3^{a}$ & $6^{\mathrm{b}}$ \\
\hline Multiple deficiency & $12^{\mathrm{c}}$ & $8^{\mathrm{d}}$ \\
\hline \multicolumn{3}{|c|}{ Postoperative hormonal deficiency } \\
\hline Single deficiency & $3^{\mathrm{e}}$ & $4^{f}$ \\
\hline Multiple deficiency & $10^{\mathrm{g}}$ & $5^{\mathrm{h}}$ \\
\hline
\end{tabular}

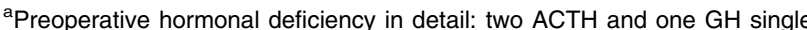
deficiency. ${ }^{\mathrm{b}}$ Four $\mathrm{GH}$, one ACTH, and one $\mathrm{FSH} / \mathrm{LH}$ single deficiency. ${ }^{\mathrm{c}}$ Four $\mathrm{ACTH}, \mathrm{GH}, \mathrm{FSH} / \mathrm{LH}$ and TSH; four $\mathrm{GH}$ and $\mathrm{FSH} / \mathrm{LH}$; two $\mathrm{ACTH}, \mathrm{GH}$, and $\mathrm{FSH} / \mathrm{LH}$; one $\mathrm{ACTH}, \mathrm{FSH} / \mathrm{LH}$, and $\mathrm{TSH}$; one $\mathrm{ACTH}$ and $\mathrm{FSH} / \mathrm{LH}$ multiple deficiency. ${ }^{d}$ One ACTH and GH, one ACTH and FSH/LH; two ACTH, GH, $\mathrm{FSH} / \mathrm{LH}$, and TSH; one $\mathrm{GH}, \mathrm{FSH} / \mathrm{LH}$, and $\mathrm{TSH}$; three $\mathrm{GH}$ and $\mathrm{FSH} / \mathrm{LH}$ multiple deficiency. ${ }^{e}$ Postoperative hormonal deficiency in detail: two $\mathrm{GH}$ and one $\mathrm{FSH} / \mathrm{LH}$ single deficiency. ${ }^{\mathrm{f}}$ three $\mathrm{GH}$ and one ACTH. ${ }^{9}$ Four ACTH, $\mathrm{FSH} / \mathrm{LH}$, and TSH; three ACTH, FSH/LH, GH, and TSH, two FSH/LH and $\mathrm{GH}$; one $\mathrm{FSH} / \mathrm{LH}$ and TSH. ${ }^{\mathrm{h}} \mathrm{One} \mathrm{ACTH}, \mathrm{FSH} / \mathrm{LH}, \mathrm{GH}$, and TSH; one ACTH and $\mathrm{FSH}$; one $\mathrm{ACTH}$ and $\mathrm{GH}$; one $\mathrm{FSH} / \mathrm{LH}$ and $\mathrm{TSH}$, one $\mathrm{GH}$ and $\mathrm{TSH}$.

factors. Hazard ratios were calculated to show clinically meaningful changes in significant variables (Table 3). In contrast, gender, invasion of the cavernous sinus, preoperative hypopituitarism, preoperative levels of FSH, LH and of the $\alpha$-subunit, postoperative hyposomatotropism, and postoperative remnant tumor (and its size in each diameter) had no independent prognostic value (Table 2).

\section{Pathological findings}

The mean Ki-67 LIm and Ki-67 LIp values of the 28 adenomas examined were $1.20 \pm 1.05 \%$ and $2.01 \pm$ $1.54 \%$ respectively. There was no significant difference in operated GSAs outcome, in terms of either Ki-67 $\operatorname{LIm}(P=0.89)$ or Ki-67 LIp $(P=0.73$; Fig. 3). Immunocytochemical analysis demonstrated the presence of

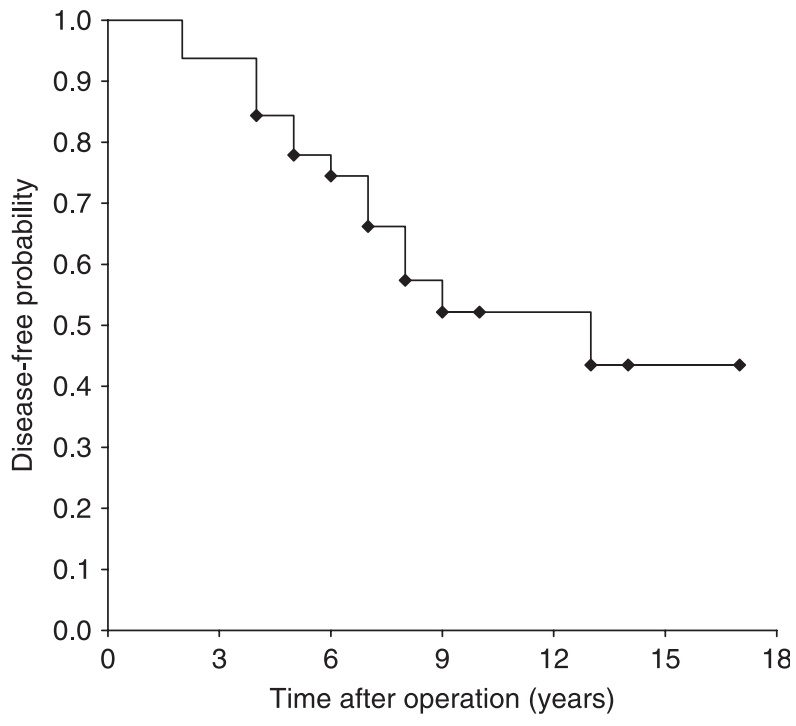

Figure 2 Kaplan-Meier curves showing the cumulative incidence of recurrence. Black lozenges indicate times at which the patient was last known to be free of recurrence. GSAs have a high and prolonged risk of local recurrence; a prolonged follow-up is therefore mandatory and should not be shorter than 10 years according to our results.

immunoreactivity, i.e, FSH in 18 adenomas, LH in 5 adenomas, $\alpha$-subunit in 3 adenomas, FSH and $\alpha$-subunit in 3 adenomas, FSH, LH and the $\alpha$-subunit in 1 adenoma, and hCG in 2 adenomas.

\section{Discussion}

The high rate of recurrence or relapse after surgery is a hallmark of GSAs. In the absence of traditional biochemical markers that permit follow-up, we aimed to identify specific prognostic factors for individual cases of the tumors. Few studies have investigated the

Table 2 Univariate analysis using the log-rank test. The rate of recurrence is correlated with tumor size $(P=0.015)$ and a young age at surgery $(P=0.027)$.

\begin{tabular}{lrc}
\hline Parameters & $\boldsymbol{b}$ & $\boldsymbol{P}$ (univariate) \\
\hline Age at surgery & -0.066 & 0.027 \\
Gender & -0.877 & 0.132 \\
Invasion of the cavernous sinus & 0.133 & 0.309 \\
AP diameter & 0.134 & 0.015 \\
TR diameter & 0.087 & 0.092 \\
RC diameter & 0.062 & 0.024 \\
Remnant tumor & 1.135 & 0.158 \\
Remnant AP diameter & 0.094 & 0.059 \\
Remnant TR diameter & 0.012 & 0.727 \\
Remnant RC diameter & 0.059 & 0.251 \\
Postoperative hyposomatotropism & 0.998 & 0.083 \\
Preoperative hypopituitarism & -0.396 & 0.450 \\
Preoperative FSH level & -0.024 & 0.916 \\
Preoperative LH level & 0.114 & 0.833 \\
Preoperative $\alpha$-subunit level & -0.461 & 0.509 \\
\hline
\end{tabular}


Table 3 Hazard ratios: each $5 \mathrm{~mm}$ increase in antero-posterior (AP) diameter is associated with a doubling of the hazard ratio. The age at surgery is negatively correlated with the rate of recurrence.

\begin{tabular}{lccc}
\hline Parameters & Hazard ratio & $\mathbf{9 5 \%} \mathbf{C l}$ & $\boldsymbol{P}$ value \\
\hline $\begin{array}{c}\text { AP diameter } \\
(+5 \text { mm })\end{array}$ & 2.11 & $1.16-3.83$ & 0.014 \\
$\begin{array}{c}\text { Age at surgery } \\
(+10 \text { years })\end{array}$ & 0.57 & $0.33-0.99$ & 0.047 \\
\hline
\end{tabular}

$\mathrm{Cl}$, confidence interval.

prognostic factors for R/P of non-functioning pituitary adenomas and, to date, no study has focused solely on GSAs. The Ki-67 LI, which correlates with tumor cell proliferation $(12-14,25)$, has proven to be of value in tumor prognosis (26-28). However, there is some discrepancy in the literature with regard to the relapse rate and invasiveness of pituitary adenomas. Several authors have found a correlation between the Ki-67 LI and the relapse rate $(9,22,29-34)$, while others have not $(19,35-37)$.

However, most of these studies were heterogeneous, including different types of pituitary adenoma and various postoperative therapies. In addition, the definition of tumor invasiveness was based on different criteria, such as histological detection, intraoperative inspection, and radiographic images. Moreover, the indices of proliferation used, i.e., PCNA and Ki-67, differed from one study to another. Since it has been shown that pituitary tumor invasiveness is far more clinically relevant and prognostically informative than the histological finding of dural invasion (2), in our study we defined tumor invasiveness on the basis of MRI findings.

To minimize bias, we excluded immunohistochemically mixed adenomas and focused on a series of 32 gonadotropin-secreting pituitary adenomas that had been treated exclusively by surgery. We found no correlation between the Ki-67 LI and tumor R/P, as defined by MRI findings, in our series. Thus, the Ki-67 LI cannot be used as a basis for clinical decisions in cases of GSA. Our Ki-67 LI results (average Ki-67=1.16\%) are similar to those found in previous studies (38-40),

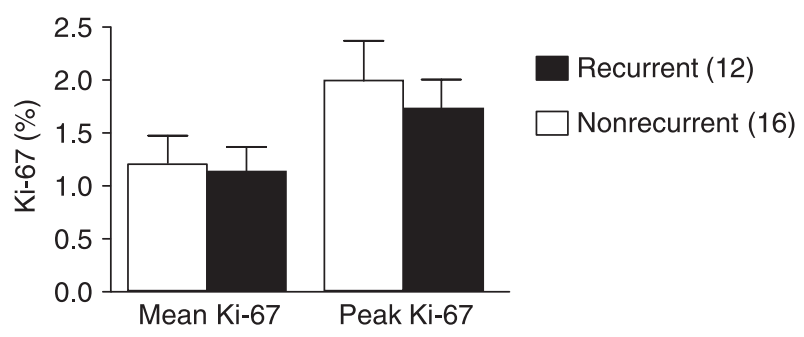

Figure 3 Mean and peak values of Ki-67 LI: Ki-67 LIm and KI-67 LIp, calculated according to the postoperative outcome of 28 patients. No significant difference between recurrent and nonrecurrent GSAs was observed: $P(\mathrm{Ki}-67 \mathrm{LIm})=0.89 ; P(\mathrm{Ki}-67 \mathrm{LIp})=$ 0.73 . The non-parametric Mann-Whitney test was used with $P$ values of 0.05 or less being considered significant. which showed that the Ki-67 LI is low in nonfunctioning pituitary tumors, including GSAs. The Ki-67 LI of breast cancer (15\%) (28), high-grade non-Hodgkin's lymphoma $(80 \%)(12,15)$, and also secreting adenomas such as corticotropinomas (3.8\%) $(2,41)$ are much higher. GSAs are known for their slow growth rate and this may account for the fact that the Ki-67 LI, when expressed solely in proliferating and dividing cells, fails to identify the risk of recurrence, in contrast to neuroendocrine tumors with a comparable low growth rate in which Ki-67 LI contributes to the scoring of aggressiveness (42). Moreover, tumor growth and relapse are complex processes that depend not only on the proliferative activity of tumor cells but also on the combined result of cell proliferation, apoptosis (43), angiogenesis $(44,45)$, degradation of connective tissue stroma by metalloproteinases (46), nuclear accumulation of $\beta$-catenin (47), and telomerase activity (48).

Recently, a trend in decreased overall tumor risks has been noted in patients with hypopituitarism operated for pituitary tumors and receiving conventional hormone treatment without GH replacement (49). Our results do not confirm the protective effect of hyposomatotropism, but the number of cases in the present study may have been too small to be of significance.

The R/P rate in the cohort studied reached $57 \%$ after 13 years. The median follow-up was 8.5 years in the non-R/P group and the median time of relapse in patients who had measurable tumor progression was 5.5 years. This indicates that the true rate of progressive growth over an extended interval is likely to be higher. Gonadotropic adenomas have a high risk of local R/P and thus a prolonged follow-up, including MRI examinations, is mandatory. The minimal duration of surveillance is difficult to ascertain, but our results suggest it should not be less than 10 years. The AP diameter is the strongest predictor of tumor $R / P$. Previous studies show that relapse is more likely in 'large' non-functional tumors (4). For GSAs, we found that each $5 \mathrm{~mm}$ increase in AP diameter was associated with a doubling of the hazard ratio, indicating a corresponding increase in the rate of $\mathrm{R} / \mathrm{P}$.

The removal of the tumor was incomplete in $81 \%$ of our patients but surprisingly remnant tumors, as well as invasion of the cavernous sinus, detected by preoperative MRI, had no influence on the rate of R/P. It has been suggested that invasiveness and recurrence do not necessarily correlate in non-functioning adenomas $(18$, 37). Indeed, the recurrence rate in corticotropic adenomas was found to be very high, although few of the tumors were invasive (50). The gonadotropic adenomas appear to behave similarly, with silent corticotrope adenomas with a high rate of persisting or recurrent disease (51) and a more aggressive behavior of non-functioning but adrenocorticotropinimmunoreactive tumor (52). Silent secreting adenomas thus appear to be more at risk of progression than true 
silent non-secreting adenomas. The small size and clinical silence of null cell adenoma and pituitary oncocytomas, frequently described in autopsies, as well as the frequency of MRI pituitary incidentalomas are an indirect indication of their indolence $(53,54)$. Taking into account disease-free survival assessments, the age at surgery correlates negatively with the rate of recurrence of GSAs. The apparent larger size of tumors in younger patients was not significant. The median time of $\mathrm{R} / \mathrm{P}$ did not change significantly across the quintiles of age, ruling out a possible underestimation of $\mathrm{R} / \mathrm{P}$ rate in older patients. In fact, a higher rate of recurrence has been reported previously in younger patients (36). This suggests that GSAs in the young may have a particular behavior that needs investigation.

\section{Conclusion}

GSAs have a high risk of $\mathrm{R} / \mathrm{P}$. The strongest indicators of a risk of $\mathrm{R} / \mathrm{P}$ appear to be the preoperative antero posterior diameter of the GSA and the age at surgery (the younger the patient, the higher the risk). No threshold can be defined to help in the management of these adenomas and in the decision regarding adjuvant radiotherapy, the frequency of MRI examinations, and the length of follow-up. The index of proliferation based on Ki-67 labeling was found to be of no value. While awaiting the identification of other pathological parameters, the two simple clinical criteria revealed by our study, i.e., the AP diameter of the tumor and the age of the patient, should be helpful in planning clinical management and radiological monitoring after first surgery of gonadotropic adenomas. Our observations need to be confirmed in larger series before definitive conclusions can be drawn.

\section{Acknowledgements}

We thank kanaya Malkani for the critical reading of this paper.

\section{References}

1 Black PM, Hsu DW \& Klibanski A. Hormone production in clinically non functioning pituitary adenomas. Journal of Neurosurgery $198766244-250$.

2 Thapar K, Kovacs F \& Scheithauer BW. Proliferative activity and invasiveness among pituitary adenomas and carcinomas: an analysis using the MIB-1 antibody. Neurosurgery $1996 \mathbf{3 8}$ 99-107.

3 Dekkers OM, Hammer S, de Keizer RJ, Roelfsema F, Shutte PJ, Smit JW, Romijn JA \& Pereira AM. The natural course of nonfunctioning pituitary macroadenomas. European Journal of Endocrinology $2007156217-224$.

4 Ebersold MJ, Quast LM \& Laws ER Jr. Long term results in transphenoidal removal of non functioning pituitary adenomas. Journal of Neurosurgery $1986 \mathbf{6 4}$ 713-719.
5 Oruçkaptan MH, Senmevsim O \& Ozcan OE. Pituitary adenomas: results of 684 surgically treated patients and review of the literature. Surgical Neurology 200053 211-219.

6 Sassolas G, Trouillas J \& Treluyer C. Management of non functioning pituitary adenomas. Acta Endocrinologica 1993129 21-26.

7 Dekkers OM, Pereira AM, Roelfsema F, Voormolen JH, Neelis KJ, Schroijen MA, Smit JW \& Romijn JA. Observation alone after transsphenoidal surgery for nonfunctioning pituitary macroadenoma. Journal of Clinical Endocrinology and Metabolism 200691 1796-1801.

8 Greenman Y, Tordjman K, Somjen D, Reider-Groswasser I, Kohen F, Ouaknine G \& Stern N. The use of beta-subunits of gonadotropin hormones in the follow-up of clinically nonfunctioning pituitary tumours. Clinical Endocrinology $1998 \mathbf{4 9}$ 185-190.

9 Ekramullah M, Saitoh Y \& Arita N. The correlation of Ki-67 staining indices with tumor doubling times in regrowing nonfunctioning pituitary adenomas. Acta Neurochirurgica 1996138 $1449-1455$.

10 Rauhut F, Clar HE \& Bamberg M. Diagnostic criteria in pituitary tumour recurrence - combined modality of surgery and radiotherapy. Acta Neurochirurgica $1986 \mathbf{8 0} 73-78$.

11 Greenman Y, Ouaknine G, Veshchev I, Reider-Groswasser II, Segev Y \& Stern N. Postoperative surveillance of clinically nonfunctioning pituitary macroadenomas: markers of tumour quiescence and regrowth. Clinical Endocrinology $2003 \mathbf{5 8}$ 763-769.

12 Brown DC \& Gatter KC. Monoclonal antibody Ki-67: its use in histopathology. Histopathology 199017 489-503.

13 Gerdes J, Schwab V \& Lemke H. Production of a mouse monoclonal antibody reactive with a human nuclear antigen associated with cell proliferation. International Journal of Cancer 198331 13-20.

14 Gerdes J, Lemke $\mathrm{H} \&$ Baisch $\mathrm{H}$. Cell type analysis of a cell proliferation-associated human nuclear antigen defined by the monoclonal antibody Ki-67. Journal of Immunology 1984133 1710-1715.

15 Gerdes J. An immunohistological method for estimating cell growth fractions in rapid histopathological diagnosis during surgery. International Journal of Cancer 198535 169-171.

16 Gerdes J, Li L \& Schlueter C. Immunobiochemical and molecular biologic characterization of the cell proliferation-associated nuclear antigen that is defined by monoclonal antibody Ki-67. American Journal of Pathology 1991138 867-873.

17 Hentschel SJ, McCutcheon IE \& Moore W. p53 and MIB-1 immunohistochemistry as predictors of the clinical behavior of nonfunctioning pituitary adenomas. Canadian Journal of Neurological Sciences $200330215-219$.

18 Honegger J, Prettin C \& Feuerhake F. Expression of Ki-67 antigen in nonfunctioning pituitary adenomas: correlation with growth velocity and invasiveness. Journal of Neurosurgery 200399 674-679.

19 Schreiber S, Saeger W \& Lüdecke DK. Proliferation markers in different types of clinically non-secreting pituitary adenomas. Pituitary $19991213-220$.

20 Turner HE \& Wass JA. Are markers of proliferation valuable in the histological assessment of pituitary tumours? Pituitary 19991 $147-151$.

21 Croue A, Beldent V \& Rousselet MC. Contribution of immunohistochemistry, electron microsopy, and cell culture to the characterisation of nonfunctioning pituitary adenomas: a study of 40 cases. Human Pathology 199223 1332-1339.

22 Hsu DW, Hakim F \& Biller BMK. Significance of proliferating cell nuclear antigen index in predicting pituitary adenoma recurrence. Journal of Neurosurgery $1993 \mathbf{7 8} 753-761$.

23 Knosp E, Kitz K \& Perneczky A. Proliferation activity in pituitary adenomas: measurement by monoclonal antibody Ki-67. Neurosurgery 198925 927-930.

24 Mastronardi L, Guiducci A \& Puzzilli F. Lack of correlation between Ki-67 labelling index and tumor size of anterior pituitary adenomas. BMC Cancer 2001112. 
25 Burger PC, Shibata T \& Kleihues P. The use of the monoclonal antibody Ki-67 in the identification of proliferating cells. American Journal of Surgical Pathology 198610 611-617.

26 Charpin C, Andrac L \& Vacheret H. Multiparametric evaluation (SAMBA) of growth fraction (monoclonal Ki-67) in breast carcinoma tissue sections. Cancer Research $1988 \mathbf{4 8} 4368-4374$.

27 Hopf NJ, Bremm J \& Bohl J. Image analysis of proliferating cells in tumors of the human nervous system: an immunohistological study with the monoclonal antibody Ki-67. Neurosurgery 199435 917-923.

28 Keshgegian AA \& Cnaan A. Proliferation markers in breast carcinoma. Mitotic figure count, S phase fraction, proliferating cell nuclear antigen, Ki-67 and MIB-1. American Journal of Clinical Pathology 1995104 42-49.

29 Kontogeorgos G. Predictive markers of pituitary adenoma behavior. Neuroendocrinology 200683 179-188.

30 Mizoue T, Kawamoto H \& Arita K. MIB-1 immunopositivity is associated with rapid regrowth of pituitary adenomas. Acta Neurochirurgica 1997139 426-432.

31 Pizarro CB, Olivieira MC \& Coutinho LB. Measurement of Ki-67 antigen in 159 pituitary adenomas using the MIB-1 monoclonal antibody. Brazilian Journal of Medical and Biological Research 2004 37 235-243.

32 Shibuya M, Saito F \& Miwa T. Histochemical study of pituitary adenomas with Ki-67 and anti-DNA polymerase alpha monoclonal antibodies, bromodeoxy-uridine labeling, and nucleolar organizer region counts. Acta Neuropathologica $1992 \mathbf{8 4}$ 178-183.

33 Tanaka Y, Hongo K \& Tada T. Growth pattern and rate in residual nonfunctioning pituitary adenomas: correlation among tumor volume doubling time, patient age, and MIB-1 index. Journal of Neurosurgery 200398 359-365.

34 Zornitzki T, Knobler H \& Nass D. Increased MIB-1/Ki-67 index as a predictor of an aggressive course in a case of prolactinoma. Hormone Research 200461 111-116.

35 Espay AJ, Azzarelli B \& Williams L. Recurrence in pituitary adenomas in childhood and adolescence. Journal of Child Neurology $200116364-367$.

36 Losa M, Franzin A \& Mangili F. Proliferation index of nonfunctioning pituitary adenomas: correlations with clinical characteristics and long term follow-up results. Neurosurgery $2000 \quad \mathbf{4 7}$ 1313-1319.

37 Yonezawa K, Tamaki N \& Kokunai T. Clinical features and growth fractions of pituitary adenoma. Surgical Neurology $1997 \mathbf{4 8}$ 494-500.

38 Nagashima T, De Armond SJ \& Murovic J. Immunocytochemical demonstration of S-Phase cells by anti-bromodeoxyuridine monoclonal antibody in human brain tumor tissue. Acta Neuropathologica 198567 155-159.

39 Landolt AM, Taichiro S \& Kleihues P. Growth rate of human pituitary adenomas. Journal of Neurosurgery 198767 803-806.
40 Carboni P Jr, Detta A \& Hitchcock ER. Pituitary adenoma proliferative indices and risk of recurrence. British Journal of Neurosurgery 19926 33-40.

41 Pegolo G, Buckwalter JG \& Weiss MH. Pituitary adenomas. Correlation of the cytologic appearance with biologic behavior. Acta Cytologica 199539 887-892.

42 Heitz PhU, Komminoth P, Perren A, Klimstra DS, Dayal Y, Bordi C, Lechago J, Centeno BA \& Klöppel G. Pancreatic endocrine tumours: introduction. In World Health Organization Classification of Tumours. Pathology and Genetics of Tumours of Endocrine Organs, ch 4, pp 177-182. Eds R Lloyd, R Dehellis, P Heitz and C Eng. Lyon: IARC Press, 2004.

43 Nakabayashi H, Sunada I \& Hara M. Immunohistochemical analyses of cell cycle-related proteins, apoptosis, and proliferation in pituitary adenomas. Journal of Histochemistry and Cytochemistry $2001491193-1194$.

44 Turner HE, Nagy Z \& Gatter KC. Angiogenesis in pituitary gland. Journal of Clinical Endocrinology and Metabolism 200085 11591162.

45 Turner HE, Nagy Z \& Gatter KC. Proliferation, bcl-2 expression and angiogenesis in pituitary adenomas: relationship to tumour behaviour. British Journal of Cancer 200082 1441-1445.

46 Turner HE, Nagy Z \& Esiri MM. Role of matrix metalloproteinase 9 in pituitary tumor behavior. Journal of Clinical Endocrinology and Metabolism 200085 2931-2935.

47 Semba S, Han SY \& Ikeda H. Frequent nuclear accumulation of beta-catenin in pituitary adenoma. Cancer 200091 42-48.

48 Yoshino A, Katayama Y \& Fukushima T. Telomerase activity in pituitary adenomas: significance of telomerase expression in predicting pituitary adenoma recurrence. Journal of NeuroOncology 200363 155-162.

49 Erfwith EM, Bulow B \& Mikoczy Z. Incidence of a second tumor in hypopituitary patients operated for pituitary tumors. Journal of Clinical Endocrinology and Metabolism 2001 86 659-662.

50 Mindermann T \& Wilson CB. Pediatric pituitary adenomas. Neurosurgery 199536 259-269.

51 Scheithauer BW, Jaap AJ, Horvath E, Kovacs K, Lloyd RV, Meyer FB, Laurs ER Jr \& Young WF Jr. Clinically silent corticotroph tumors of the pituitary gland. Neurosurgery 200447 723-729.

52 Bradley KJ, Wass JA \& Turner HE. Non-functioning pituitary adenomas with positive immunoreactivity for ACTH behave more aggressively than ACTH immunonegative tumours but do not recur more frequently. Clinical Endocrinology 200358 59-64.

53 Mavrakis AN \& Tritos NA. Diagnostic and therapeutic approach to pituitary incidentaloma. Endocrine Practice $200410438-444$.

54 Buurman H \& Saeger W. Subclinical adenomas in post mortem pituitaries: classification and correlation to clinical data. European Journal of Endocrinology $2006 \mathbf{1 5 4} 753-758$.

Received 15 February 2007

Accepted 3 May 2007 